\title{
EL DEVENIR-HUMANO DEL ANIMAL JACQUES DERRIDA Y LA DECONSTRUCCIÓN DEL LOGOS
}

\author{
Nicola Zengiaro \\ Universidad de Santiago de Compostela
}

\begin{abstract}
Resumen
El antropocentrismo metafísico delineado por autores como Kant, Heidegger, Lévinas y Lacan nos permite situarlos en una misma línea que define el umbral entre el hombre y el animal: el poder de autorreferencia. Este poder-tener un "yo" o poder-ser un "yo", la vocación a la egoidad, es lo que se le niega al animal, es decir, la experiencia de la auto-posición. La facultad de referirse a sí mismo, que coincide con la responsabilidad del sujeto y con lo que (en la metafísica) eleva el hombre por encima de todos los vivientes, funda su poder sobre los animales. Este es el principio a partir del cual se reinterpretan tales posturas filosóficas, poniéndolo en relación con la lingüística y el psicoanálisis. La presente investigación pretende responder a la pregunta “¡cómo deviene humano el animal?" a partir de las reflexiones de Jacques Derrida. La antropogénesis es el proceso a través el cual un ejemplar de Homo sapiens deviene sujeto, es decir, un cuerpo animal capaz de decir de sí mismo "yo".
\end{abstract}

Palabras clave: Antropogénesis, Antropocentrismo metafísico, Deconstrucción, Filosofía del lenguaje.

\begin{abstract}
Metaphysical anthropocentrism delineated by authors such as Kant, Heidegger, Lévinas and Lacan allows us to place them according to the definition of the threshold between the man and the animal - the power of self-reference. This power of having an 'I' identity, to recognize ourselves as such, our vocation to selfhood, it is what is denied to animals, in other words, the experience/ability of self-position. The faculty to recognize and allude to ourselves which coincides with the individual responsibility and with which (in metaphysics) raises the man above every living being. It establishes the man's power above animals. This is the beginning from which some philosophical stances are reinterpreted, relating the man to linguistics and psychoanalysis. The recent research expects to answer the question of 'how does animal turn into human?' based on Jacques Derrida thought. Anthropogenesis is the process through which a specimen of Homo Sapiens becomes a person, that is to say, an animal able to identify itself as 'I.'
\end{abstract}

Keywords: Anthropogenesis, Metaphysical anthropocentrism, Deconstruction, Philosophy of language. 


\section{Prefacio: la profecía de Derrida}

Jackie Derrida (I930-2004), conocido por el nombre de Jacques, fue uno de los filósofos más importantes del siglo xx. Su pensamiento filosófico se puede dividir en dos períodos que se construyen a través de sus escritos y en las conferencias que dio en varias universidades: el primero es el Derrida de la gramática y la deconstrucción a través del cual "nada existe fuera del texto"; el segundo, a partir de los años ochenta, se centra más en el tema de la vida y la muerte, o la animalidad y la ética, donde utiliza palabras que son "palabras desnudas", del corazón. El presente artículo cruza los dos períodos, pero se centrará en el "segundo" Derrida, del que hemos podido repensar la animalidad y su ontología gracias al trabajo que ha realizado especialmente a través de sus últimas lecciones, los escritos póstumos que recogen sus notas y seminarios. Durante su viaje como filósofo, el 22 de septiembre de 200 en Frankfurt recibió el premio Theodor W. Adorno, con la mención de Bernhard Waldenfels y Jürgen Habermas. El discurso de Jacques Derrida, en esa ocasión, ilumina el pensamiento que desarrolló a lo largo de su vida, en un compendio ejemplar de un libro ideal de sueños que habría escrito y que, en su estilo único, expresó en siete capítulos con títulos provisionales. El séptimo capítulo, de este libro que soñaba con escribir, habría sido escrito sobre la animalidad, o más propiamente, de lo que se llama el "Animal". Este tema suyo, su último y fundamental tema que representaba su más preciado apego a la vida, que debido a una enfermedad le estaba abandonando, abre las puertas a toda una serie de consecuencias éticas que hoy en día forman parte de nuestro más alto pensamiento filosófico.

Es una pista para seguir que dejó al descubierto y a la vista, con el fin de sacar a la luz algunos oscuros fundamentos de la filosofía sobre el tema de la soberanía, el dominio del hombre sobre la naturaleza, el concepto de dignidad y autonomía del hombre, la compasión entre el hombre y el animal, la animalidad en el hombre. Derrida abre en este discurso un camino hacia el futuro, dentro del cual la deconstrucción del ser humano como gobernante, del sometimiento que ha tenido lugar hacia los demás seres vivos, tiene lugar, en la reconstrucción profética de un desarrollo que quiso dejar de lado la filosofía de la animalidad y que en un futuro próximo, constituirá un post-humano que ya en es- 
tos años es necesario para la reconstrucción, para un futuro que vea la coparticipación de todos los seres vivos en un solo mundo, de una sola manera, en el que existimos. La crítica, la deconstrucción, la huella, que se deja ver al recibir uno de los premios más importantes de la filosofía, es precisamente la de la dignidad del hombre a través de la reapropiación de su animalidad. ¿Por qué la animalidad? Porque la animalidad, y los animales, todos ellos, obligados a una referencia unívoca que los aplasta y aniquila bajo el nombre de Animal, fueron los más sumisos, porque no fueron vistos, porque no fueron tomados en consideración, por lo tanto privados de su vida, dignidad, existencia, en realidad nos rodean, siempre nos han poseído, y a través de los cuales, en la negación de su mundo, el hombre, el concepto de humanidad, podría ser construido en la violencia que niega la humanidad misma. En la animalidad, la filosofía pura tiene vida, la filosofía de la alteridad, la misma filosofía que se ocupa del Otro, de todos los otros posibles y que, por lo tanto, se expande infinitamente al campo de la existencia de la posibilidad última y totalizadora. Derrida logra, a través de su pensamiento sobre la animalidad y el lenguaje, dar vida a la filosofía que ha sido silenciada por todos los filósofos anteriores.

La conclusión de su discurso en Frankfurt sugiere que las premisas de la animalidad, que hasta ahora han sido excluidas y de las que los filósofos nunca se han avergonzado y han declinado toda responsabilidad, deben ser desarrolladas para una revolución pensante y activa que necesitamos en la cohabitación con esos otros seres vivos llamados "animales"; la filosofía que vendrá es precisamente el intento de pensar una salida del humanismo.

\section{INTRODUCCIÓN}

El hombre existe históricamente tan solo en esta tensión; puede ser humano sólo en la medida en que trascienda y transforme el animal antropóforo que lo sostiene; sólo porque, a través de la acción negadora, es capaz de dominar y, eventualmente, destituir su misma animalidad ${ }^{1}$.

Lo que caracteriza a Occidente sería, según Derrida, un cierto antropocentrismo. En su perspectiva esta temática revela el dominio que

1 G. Agamben, Lo abierto. El hombre y el animal, Buenos Aires, Adriana Hidalgo, 2002, p. 28. 
subyace a la postura antropocéntrica, la cual sería delineada por la centralidad del hombre, su propiedad, su identidad y su superioridad ${ }^{2}$. Estas connotaciones definen el poder del hombre que en este artículo intentaremos deconstruir.

La argumentación derridiana, sobre todo a partir de los años ochenta ${ }^{3}$, afirma que el poder del hombre se construye sobre una reducción simétrica de lo animal. ¿Qué significa esto? El filósofo argelino quiere mostrar que las especificidades humanas coinciden con lo que se sustrae al animal, es decir, por negación: el poder de hablar, de pensar, de reír, de experimentar la muerte, de procesar el luto. El logocentrismo (el poder-tener el logos), es, para Derrida, otra forma de referirse a este antropocentrismo.

III. El PODER DEL LOGOS

Este poder-tener el logos, definido como antropocentrismo metafísico ${ }^{4}$, puede articularse en dos puntos:

a) La pretensión de trazar una oposición clara, una frontera única y compacta, una sola línea de demarcación entre los que dicen "nosotros, los hombres" y los vivientes que estos mismos llaman "los animales";

b) La pretensión de amontonar todos los otros vivientes, los que los hombres no reconocen como sus semejantes, bajo un único concepto homogéneo al singular general de "Animal", a pesar de las innegables diferencias.

Surge inmediatamente una complicación que puede ser pensada como un síntoma lacaniano, es decir, algo que remite a un fenómeno latente, a lo que no es manifiesto. Este problema remarca el tema de la remoción (análoga al tratamiento de la escritura en los primeros escritos derridianos) enfocándolo como desarrollo de una amenaza a la originariedad y la pureza del logos. La remoción de la cual estamos hablando es el trata-

2 C. Furlanetto y E. Villalta (ed.), Animali, uomini e oltre. A partire da La Bestia e il Sovrano di Jacques Derrida, Milán, Mimesis, 2011.

3 M. Ferraris, Ricostruire la decostruzione. Cinque saggi a partire da Jacques Derrida, Milán, Bompiani, 2010.

4 C. Di Martino, Figure dell'evento. A partire da Jacques Derrida, Milán, Guerini, 2009. 
miento de lo que es "Animal". Antes de todo, entonces, podemos definir el "logocentrismo" como la tendencia del discurso teórico a remover las propias condiciones materiales. Un discurso crítico o deconstructivo deberá, pues, poner el acento sobre esta remoción.

\section{REMOCIÓN/SECRETO Y RESPONSABILIDAD/ÉTICA}

En nuestra cultura, el hombre [...] ha sido siempre el resultado de una división, y, a la vez, de una articulación de lo animal y lo humano, en la cual uno de los dos términos de la operación era también lo que estaba en juego. Volver inoperante la máquina que gobierna nuestra concepción del hombre significaría, por lo tanto, ya no buscar nuevas articulaciones — más eficaces o más auténticas-, sino exhibir el vacío central, el hiato que separa — en el hombre- el hombre y el animal, arriesgarse en este vacío: suspensión de la suspensión, shabbat tanto del animal como del hombre ${ }^{5}$.

En la obra de Derrida se puede leer la remoción como un secreto -en términos del propio autor- que custodia el poder humano. Trataremos, entonces, la remoción como un secreto ${ }^{6}$, y explicaremos cómo se puede desarrollar esta analogía a lo largo de sus escritos.

Efectivamente el tratamiento de lo animal, es decir, todo lo que subyace a la relación hombre-animal, ocurre en secreto, lo cual revela en el fondo la experiencia del sacrificio. ¿Por qué?

[...] Ante todo, en el sentido hebreo del término, korban, que quiere decir más bien la aproximación y que abusivamente se traduce por sacrificio, sino en el sentido en el que el sacrificio supone matar a lo único en lo que tiene de único, de irremplazable y de más valioso. Se trata pues también de la substitución imposible, de lo insustituible, pero también de la substitución del animal por el hombre -y asimismo, sobre todo, en esta misma substitución imposible, de lo que vincula a lo sagrado con el sacrificio y al sacrificio con el secreto ${ }^{7}$.

¿Qué significa esto? En el cuento de Abraham e Isaac, cuando este último le pregunta dónde se encuentra el cordero (que es el símbolo clásico que sustituye el cuerpo carnal del hijo de Dios) para el sacrificio, Abraham

5 G. Agamben, Lo abierto. El hombre y el animal, Buenos Aires, Adriana Hidalgo, 2002, p. 167.

6 J. Derrida y M. Ferraris, Il gusto del segreto, Roma-Bari, Laterza, 1997.

7 J. Derrida, Dar la muerte, Barcelona, Paidós, 2000, p. 61. 
dice que «Dios proveerá, Dios procurará el cordero para el holocausto». Lo que emerge desde la remoción que hay en esta oración es que Dios es el signo mismo de la remoción. Abraham —el padre - remite a algo que no está allí, algo que transciende la escena y que soluciona el enigma de no poder contestar en falso a su hijo que se acerca inconscientemente hacia su muerte, su sacrificio, como un animal, el cual no puede saber lo que está pasando realmente en su relación con el hombre, con el sujeto que sustituye con su sacrificio.

Como es sabido, Abraham guarda su secreto (el secreto de que va a matarlo) pero también responde a Isaac. «Ni se calla ni miente. No dice lo no-verdadero", escribe Derrida en Dar la muerte.

¿Cómo se puede decir lo no-verdadero? Hablando de la remoción, de lo que se refiere a otra cosa, cuando nos referimos a un "algo" que no sabemos si existe, del cual no sabemos nada y no podemos decir nada sobre ello que no sea una interpretación (hablando de un signo que remite a otro signo infinitamente). Por esta razón Derrida afirma que la remoción es una cuestión originaria ${ }^{8}$. Esta remoción es, en el contexto que estamos investigando, el Animot - la unión de animoux, animal, y mot, palabra - definido como phone semantike. Hablando del animal en general nosotros seres humanos utilizamos conceptos universales que son vacíos y que al mismo tiempo pretenden alcanzar la individualidad, unicidad e irrepetibilidad del animal en cuanto tal. Esto significa además que cuando nos referimos al animal, cuando hablamos del animal, siempre ocultamos la imposibilidad de poder hablar del animal que está frente a nosotros; porque de aquel animal particular no sabemos nada y por esta razón siempre decimos lo no-verdadero.

Prosiguiendo nuestra argumentación, y dejando por un momento de lado la cuestión del Animot, veamos que:

[Abraham] debe guardar el secreto (es su deber) pero es también un secreto que debe guardar, doble necesidad porque no puede sino guardarlo, en el fondo: no lo conoce, sabe que lo hay, pero ignora su sentido y sus razones últimas. Está obligado a mantener el secreto porque está incomunicado?.

8 J. Derrida, Ogni volta unica, la fine del mondo, Milán, Jaca Book, 2005.

9 J. Derrida, Dar la muerte, Barcelona, Paidós, 2000, p. 62. 
Nosotros debemos guardar el secreto (este síntoma lacaniano), porque si no, el hombre como lo conocemos está amenazado, nosotros mismos estamos amenazados, lo que nos constituye esencialmente, es decir, el logos. Pero,

Por decirlo en otras palabras, Abraham transgrede el orden de la ética. Porque la ética, según Kierkegaard, no tiene expresión más elevada que la que nos vincula con nuestros prójimos y con los nuestros (éstos pueden ser la familia, mas también la comunidad concreta de los amigos o la nación). Al guardar el secreto, Abraham traiciona la ética. Su silencio, en todo caso el hecho de que no desvele el secreto del sacrificio solicitado no está ciertamente destinado a salvar Isaac ${ }^{10}$.

Nuestro silencio no está, en verdad, destinado a salvarnos. Hablar del Animot, de este síntoma, es transgredir el orden ético. Cada vez que hablamos del "Animal" en singular general estamos traicionando la ética. Esto porque hablamos sin decir nada y así el secreto continúa perpetuándose. Somos responsables ante los animales, cuestión que proporciona una necesidad ontológica y un deber ético.

Antes de nada, entonces, debemos preguntarnos ¿qué es la responsabilidad para Derrida? La responsabilidad se da solo cuando somos llamados a hacer lo imposible, hacer más de lo que podemos, es decir, solo cuando contestamos a una llamada que se contradice. Específicamente se habla de la antinomia: cuando ambas soluciones propuestas, antitéticas, se presentan como posibles. Por esta razón, no se trata de seguir una regla, una praxis, un programa. La responsabilidad tiene lugar cuando se tienen que hacer dos cosas contrarias e igualmente necesarias:

a) Dar voz (logos) a los animales deconstruyendo lo humano;

b) Salvar nuestro constructo de "humanidad" dejando morir (desaparecer) a los animales en el Animot como Abraham hace con Isaac.

Pero, si esto es verdad, si la cesura entre lo humano y lo animal pasa sobre todo por el interior del hombre, entonces la cuestión del hombre - y del "humanismo"- debe ser formulada en nuevos términos ${ }^{11}$.

11 G. Agamben, Lo abierto. El hombre y el animal, Buenos Aires, Adriana Hidalgo, 2002, p. 35. 
Para esta elección no es suficiente ejercitar un saber o un poder. Una decisión responsable, según Derrida, delinea una discontinuidad con el orden del saber y del poder para que sea lo más pura posible. Hay responsabilidad solo en el orden del imposible, a condición de resistir a la aporía de dos imperativos.

¿Cómo justificaríamos el sacrificio de todos los gatos del mundo al gato que alimentamos en casa todos los días durante años, mientras que otros gatos mueren de hambre a cada instante? ¿Y el de otros hombres? [...] $\mathrm{Y}$, sin embargo, cumplimos también con nuestro deber obrando así. No hay lengua, razón, generalidad o mediación para justificar esta responsabilidad última que nos conduce hacia el sacrificio absoluto. Sacrificio absoluto que no es el sacrificio de la irresponsabilidad sobre el altar de la responsabilidad, sino el sacrificio del deber más imperativo (aquél que vincula con el otro como singularidad en general) en beneficio de otro deber absolutamente imperativo que nos vincula con cualquier/radicalmente otro ${ }^{12}$.

Podemos concluir que este movimiento define el sacrificio de los dos -el Hombre y el Animal-; el dar-la-muerte-al-otro dándose la muerte, mortificándose para dar esta muerte en ofrenda sacrificial a nosotros mismos. «iEsta es la terrible responsabilidad de la soledad!»

\section{Antropogénesis}

Trataremos, a continuación, de deconstruir el poder del antropocentrismo metafísico:

A pesar de las inmensas diferencias o contradicciones que los separan y que yo sería el último en querer minimizar, Kant, Heidegger, Lévinas y Lacan comparten, en lo que se refiere a lo que denominan "el animal", un número considerable de lo que yo llamaría creencias y que, si preferís, podríais denominar axiomas o prejuicios, presunciones o presupuestos. Me gustaría intentar mostrar en todo caso que, al igual que Descartes, aquéllos piensan que, a diferencia de nosotros los hombres (diferencia que está determinada así), el animal no habla ni responde, que su capacitad de emitir señales es ajena al lenguaje y se encuentra limitada, fijada por un programa. [...] A título de lo que no varía y del rasgo común, añadiré 
asimismo lo siguiente que lo anima todo y ha de irrigarlo todo: a saber, que el sacrificio imprime un latido vital en el corazón de todos estos discursos. Se trata de cuatro pensamientos de la experiencia sacrificial, cuatro pensamientos que no se reunirían consigo mismos, de manera consecuente y seguida, si no reafirmasen la necesidad del sacrificio ${ }^{13}$.

El centro neurálgico de la antropología cartesiana nos permite colocar a lo largo de una sola línea a Kant, Heidegger, Lévinas y Lacan. Esta antropología reside en la afirmación de un poder del “yo", es decir, el poder de hacer referencia a sí en forma deíctica, auto-deíctica para decir "soy yo" 14 .

En el ámbito de la lingüística, más concretamente en la semántica, "deíctico" es un término que remite una función de atribución al hablante, supuesta por el interlocutor, de manera que en este intercambio verbal, hablado o escrito, los roles y las perspectivas permiten identificar las cosas de forma precisa. Se puede también entender esta formulación como lo que explicita el contexto espacial y temporal de un acto lingüístico e identifica quién es el protagonista, el sujeto principal.

Este poder-tener el "yo", o el poder ser un “yo”, la vocación a la egoidad, es lo que se le niega al animal, es decir, la experiencia de la auto-posición o autotelia (desde auto y telos) auto-demostrativa. La facultad de referirse a sí mismo coincide con la responsabilidad del sujeto, y lo que (en la metafísica) eleva el hombre por encima de todos los vivientes, que funda su poder sobre los animales.

El auténtico soberano humano es el significante. [...] El hombre es sujeto del significante, sujeto sometido al significante soberano. Pero ser sujeto del significante es también ser sujeto que somete, sujeto amo, sujeto activo y que decide del significante, lo suficientemente amo en todo caso, si quieren ustedes, para ser capaz de fingir que finge y, por lo tanto, de poder plantear su poder de aniquilación de la huella. Esta soberanía es la superioridad del hombre sobre la bestia [...]. Es ahí donde el paso de lo imaginario a lo simbólico se determina como paso del orden animal al orden humano ${ }^{15}$.

13 J. Derrida, El animal que luego estoy si(gui)endo, Madrid, Trotta, 2008, pp. 109 y 111.

14 G. Agamben, Che cos'è la filosofia?, Macerata, Quodlibet, 2016, p. 24.

15 J. Derrida, La bestia y el soberano. Volumen I (2001-2002), Buenos Aires, Manantial, 2010, p. 157. 
Y prosigue con la denuncia del síntoma:

Pero vayamos más lejos y planteemos un tipo de cuestión que me hubiera gustado generalizar, si hubiera tenido tiempo. No se trata tanto de preguntar si se tiene derecho a negarle este o aquel poder al animal (palabra, razón, experiencia de la muerte, duelo, cultura, institución, política, técnica, vestido, mentira, fingimiento de fingimiento, borradura de la huella, don, risa, llanto, respeto, etc. - la lista es necesariamente indefinida, y la más poderosa tradición filosófica en la que vivimos ha negado todo esto al «animal») cuanto de preguntarse si lo que se denomina el hombre tiene derecho a atribuir con todo rigor al hombre, de atribuirse, por lo tanto, aquello que le niega al animal y si tiene acerca de esto alguna vez el concepto puro, riguroso, indivisible en cuanto tal. Así, suponiendo incluso, conceso non dato, que el «animal» sea incapaz de borrar sus huellas, ¿con qué derecho conceder este poder al hombre, al «sujeto del significante»? $¿ Y$ sobre todo desde un punto de vista psicoanalítico? Cualquier hombre pude, ciertamente, tener conciencia, en un espacio de fenomenalidad dóxica, de borrar sus huellas. Pero ¿quién juzgará alguna vez la efectividad de este gesto? ¿Es necesario que toda huella borrada, conscientemente, puede dejar una huella de su borradura de cuyo síntoma (individual o social, histórico, político, etc., e incluso técnico — nunca se puede estar seguro de haber borrado algo en una computadora, etc.) podrá asegurar siempre el regreso ${ }^{16}$

\section{1. ¿Cuándo deviene humano el animal?}

Lo que sucede es que:

i) El hombre miente (dice la no-verdad) ${ }^{17}$, borra las huellas, y en este sentido, deconstruir significa ver las huellas de la borradura (contra Nietzsche que trata el hombre como "el animal que promete"18);

ii) El soberano humano es el significante (el sujeto está sometido al significante).

Estos dos puntos ponen en marcha toda una tradición que va de la culpa adánica de "seres perfectos a seres humanos" a través del pecado original y, por otro lado, tiene que ver con el mito de Prometeo en el

16 Ibid., p. 163.

17 J. Derrida, Breve storia della menzogna. Prolegomeni, Roma, Castelvecchi, 2006.

18 F Nietzsche, La genealogia della morale, Milán, Adelphi, 1984, p. 45. 
que el privilegio del defecto es lo que asegura la superioridad humana y de su técnica. El segundo tema se nutre de una paradoja que se puede esquematizar en la dialéctica inmanencia-trascendencia (el cuerpo y el lenguaje): por un lado tenemos al animal, que carece de todo lo que es digno de ser relevante, y lo único que le pertenece es su propia vida y su estar en el mundo, lo cual se representa a través del cuerpo que es (inmanencia); por otro lado al hombre, que tiene el poder del lenguaje, carece de cualidades animales - y aquí se funda su humanidad en contraposición a la animalidad - y de adherencia a su vida (trascendencia) ${ }^{19}$.

$\mathrm{El}$ salto entre las dos posturas no es abrupto, sino, como veremos, es un proceso largo y constante que define la distancia entre el hombre y el animal.

\subsection{El lenguaje funda al ser humano}

En cuanto el animal no conoce ente ni no ente, abierto ni cerrado, él está fuera del ser, fuera en una exterioridad más externa que todo abierto y dentro en una intimidad más interior que toda clausura. Dejar ser lo animal significaría entonces: dejarlo ser fuera del ser. [...] Pero lo que es así dejado ser fuera del ser no es, por esto, negado o removido, no es por esto, inexistente. Es un existente, un real, que ha ido más allá de la diferencia entre ser y ente ${ }^{20}$.

En este apartado trataremos de explicar el proceso de antropogénesis (del antropocentrismo metafísico).

Para empezar, debemos preguntarnos: ¿qué es un animal? Nosotros lo sabemos todo de los animales (la mentira del punto (i)). Sabemos que el perro es fiel, que el gato es solitario, que el león es fuerte (el animal es un significante (ii) que podemos interpretar). Pero lo que sabemos, sobre todo, es que el animal es carente de algo. $\mathrm{El}$ animal es aquel viviente al que le falta algo, y el medio para definir la ausencia es siempre el hombre mismo. Entonces para saber que es un animal debemos conocer cuál es la animalidad humana ${ }^{21}$, es decir, la constitución de aquel animal que

19 F. Cimatti, Filosofia dell'animalità, Roma-Bari, Laterza, 2013.

20 G. Agamben, Lo abierto. El hombre y el animal, Buenos Aires, Adriana Hidalgo, 2002, pp. 166-167.

21 L. Caffo y F. Cimatti (Eds.), A come animale. Voci per un bestiario dei sentimenti, Milán, 
tiene solo la preocupación de diferenciarse de los otros vivientes. Esto significa que debemos, para saber realmente qué es un animal, salir del antropocentrismo ${ }^{22}$.

Siguiendo los pasos de Jacob von Uexkül123 podemos decir que el animal tiene su mundo propio (Umwelt), compuesto por dos características distintivas: a) el mundo perceptivo (Merkwelt) y b) el mundo operativo (Wirkwelt). Juntos, estos dos mundos constituyen lo que llamamos supervivencia. Estos mundos están cerrados como mónadas, porque todo lo que está fuera de esta esfera (alrededor de la pompa de jabón) de supervivencia es, para el animal, carente de significado (invisible). Ahora bien, el mundo del ser humano está compuesto de la Umwelt más lo que está fuera, lo que está alrededor, la Umgebung. Pero ¿cómo se puede hablar de la Umgebung? ¿Quién puede percibirla? Aquí está nuevamente, se presenta nuevamente, la metafísica, porque el alrededor puede percibirlo solo el ser humano (proporcionando así una jerarquía implícita).

Esta es también la estela que sigue el profesor de Uexküll, Martin Heidegger ${ }^{24}$. La diferencia entre el hombre y el animal radica en los siguientes puntos: a) el animal está condicionado y por este motivo no tiene un mundo, sino solo un ambiente entre el cual puede vivir solamente su cerrado punto de vista; b) el ser humano es libre y tiene un mundo, que es la capacidad de no adherirse a su propia vida, a su ambiente (como los instintos determinísticos de los otros animales no humanos). El hombre es un animal que sabe que es un animal y, entonces, deja de ser solamente un animal, trasciende su animalidad.

La diferencia entre la Humanitas y la Animalitas es, según Heidegger $^{25}$, el lenguaje que permite al ser humano acceder a la Lichtung (el claro) del ser. Es decir, el lenguaje permite coger el ser en cuanto tal (no como este o aquel objeto particular, sino de poseer el concepto del ser general, universal, donde, en contra de esto, el animal tiene solo relación con el particular, con lo que es determinado y finito). Este poder, esta

Bompiani, 2015.

22 L. Caffi, "I due dogmi dell'antropocentrismo", Scienze e ricerche, vol. 46, pp. 25-31.

23 J. Von Uexküll, Ambienti animali e ambienti umani, Macerata, Quodlibet, 2010.

24 M. Heidegger, Los conceptos fundamentales de la metafísica. Mundo, finitud, soledad, Madrid, Alianza, 2007.

25 M. Heidegger, Lettere sull'«umanismo», Milán, Adelphi, 2013. 
posesión que permite pasar de los entes (particulares) al ser (general) es el lenguaje ${ }^{26}$. El lenguaje es ilimitado, tiene una componente innata que podemos llamar, para favorecer la claridad analítica, "infinitud discreta" ${ }^{27}$.

Ahora bien, ser el animal del lenguaje significa ser el animal que puede tener una relación con el mundo solo a través la mediación de la palabra. En este problema se funda toda una serie de dicotomías como aquellas de cuerpo/mente, subjetividad/vida, trascendencia/ inmanencia etc. Esto significa una cosa más: tener relaciones con uno mismo (con el propio cuerpo) significa que también estas deben estar mediadas por la palabra y, por esta razón, el animal que habla no es adherente a su cuerpo y a su vida. Agamben afirma justamente que el hombre es el animal que tiene que reconocerse bumano para serlo.

\section{2. ¿Cómo deviene humano el animal?}

La antropogénesis es el proceso a través del cual un ejemplar de Homo sapiens deviene sujeto, es decir, deviene un cuerpo animal capaz de decir de sí mismo "yo". Surge inmediatamente una separación entre el yo que dice "yo" y el cuerpo del mismo "yo".

En este epígrafe esquematizaremos las tres etapas del devenir humano, mostrando las borraduras de las huellas de la remoción que subyace al lenguaje ${ }^{28}$.

Primera etapa: "El nombre".

La atribución del nombre al nacer se lleva a cabo antes de la vida social, donde existe a) el cuerpo carnal, el cual es cuidado por los padres y b) el cuerpo simbólico que se acompaña al nombre ${ }^{29}$.

Segunda etapa: "El 'no"

Cuando a) y b) se encuentran en el niño, es decir, cuando empieza a tener consciencia de lo que él mismo es, pasa una cosa particular. Pongamos un ejemplo para aclarar lo que sucede en la mente del cachorro

26 M. Heidegger, Essere e tempo, Milán, Longanesi, 2005.

27 N. Chomsky, Syntactic Structure, Berlín, Mouton de Gruyter, 2002; y What Kind of Creatures Are We?, Nueva York, Columbia University Press, 2016.

28 F. Cimatti, Filosofia dell'animalità, Roma-Bari, Laterza, 2013.

29 J. Derrida, Il segreto del nome, Milán, Jaca Book, 1997. 
humano en su primera fase, describiendo una escena del mundo animal y, después, para comparar, una en la que el lenguaje es utilizado como forma de poder sobre sí.

La abeja ve una orquídea. No la ve como un ente determinado, separado de sí, dotado de una serie de características independientes; la percibe desde el principio como el terminal implícito de una acción dotada de valor biológico. No existe por un lado la abeja y por otro la flor (un Sujeto y un Objeto) y en el medio los pensamientos de la abeja sobre lo que podría hacer con aquella flor: existe inmediatamente un flujo energético unitario abeja-flor-néctar. Las investigaciones neurológicas confirman que, al menos en el cerebro de los vivientes dotados de manos y extremidades en general, a la visión de un objeto aprehensible se activan no solo las áreas visivas, sino también y contemporáneamente aquellas motoras, es decir, aquellas que controlan los movimientos de las manos ${ }^{30}$. Ver y actuar proceden juntos. Es decir que «los animales se hallan a tono con sus cuerpos de un modo distinto, y más vital, que nosotros» ${ }^{31}$.

Un Homo sapiens, sin embargo, deviene sujeto - entendido como proceso de antropogénesis, o, la manera de pasar de ser un cuerpo animal a ser humano- cuando su cuerpo animal es capaz de decir de sí mismo “yo". El papel fundamental que juega el lenguaje, y que diferencia al ser humano del animal es el uso normativo que utiliza el animal humano para controlarse; como forma de poder sobre su cuerpo ${ }^{32}$. Pongamos un ejemplo.

Hay en las sillas frente a la mesa un gato y un niño. El niño le dice al gato “no, no puedes subir a la mesa”. El niño repite lo que escuchó a los adultos, usa el lenguaje como forma de poder, para prohibir algo a una corporeidad, aquella del gato. En otra ocasión sucede que el niño tiene hambre. Sabe que en la despensa hay chocolate, sabe que no hay adultos en el entorno y que, si se mueve rápidamente, nadie se dará cuenta. Pero sabe que su madre no quiere que él coma antes de cenar, porque si no, ella se enfadará con él. Existe el hambre y existe el chocolate. Pero existe

30 F. Cimatti, Filosofia dell'animalità, Roma-Bari, Laterza, 2013, p. 34.

31 J. M. Ferrater y P. Cohn, Ética aplicada. Del aborto a la violencia, Madrid, Alianza, 1981, p. 74.

32 M. Hauser, N. Chomsky, T. Fitch, "The Faculty of Language: What Is It, Who Has It, and How Did It Evolve?”, en Science's Compass, vol. 298, 2002. 
también aquel "no", que aprendió a utilizar con el gato. Ahora estamos en el punto. El niño está abriendo la despensa, pero llega en su mente aquel "no". No es necesario que se lo imagine, eso suena durante sus improvisos e irresolutos gestos. Al final, después de muchas dudas, abandona su actividad y el chocolate queda en la despensa. Ahora el lenguaje no controla el cuerpo del gato, el "no" controla su mismo cuerpo, como antes hacían sus padres con él ${ }^{33}$. El acto lingüístico del "no" escinde en dos la corporeidad del niño.

Estos ejemplos ilustran cómo, a través del lenguaje, los seres humanos se desprenden de la corporeidad y son capaces de observarse desde fuera; en el proceso de antropogénesis del que hablábamos antes, la animalitas significa ser el cuerpo que eres y, más allá de este cuerpo, no hay nada (inmanencia del cuerpo a sí mismo). La humanitas consiste en esta duplicación por la cual el cuerpo que eres ahora es el cuerpo que tienes, un cuerpo-objeto a disposición de aquella extraña identidad capaz de decir "yo" (trascendencia del sujeto respeto al cuerpo $)^{34}$. El lenguaje proporciona el poder de salir de su "ambiente" natural y entrar en el "mundo". Ser un cuerpo significa no saber que se es dicho cuerpo. $Y$ vemos como este acto lingüístico es la capacitad de aplicar el poder y la violencia del lenguaje a uno mismo, lo que llamamos "autocontrol".

Es ahí donde, a la filosofía tradicional del sujeto, la subjetidad, como orden del significante desde el lugar del Otro, se le habría escapado como relaciones entre el hombre y el animal. Tal es al menos la alegación de Lacan en el momento en que reintroduce sutilmente la lógica del antropocentrismo y refuerza firmemente el fijismo del cogito cartesiano como tesis sobre el animal-máquina en general ${ }^{35}$.

Y citando a Lacan subraya que:

Así, es de un lugar distinto de la Realidad a la que concierne de donde la Verdad obtiene su garantía: es de la Palabra ${ }^{36}$.

El único cuerpo que se puede tener es aquel imaginario ofrecido por la

33 F. Cimatti, Filosofia dell'animalità, Roma-Bari, Laterza, 2013, 36-37.

34 F. Cimatti, Il taglio. Linguaggio e pulsione di morte, Macerata, Quodlibet, 2015; y F. Cimatti, (ed.), “Animalità e psicoanalisi. Dalla parola al corpo", en "Psicoanimot". Animot. L'altra filosofia, vol. III, núm. 6, pp. 10-34.

35 J. Derrida, J., La bestia y el soberano. Volumen I (2001-2002), Buenos Aires, Manantial, 2010, p. 157.

36 J. Lacan, Escritos. Vol 2, Buenos Aires, Siglo XXI, 2002, p. 787. 
mirada del otro. Significa salir de sí, mirarse desde fuera. Este problema se anuncia en el encuentro entre Derrida que está desnudo en frente de su gata en el Animal que donc je suis. Esto remite a la mirada del animal; ver a la gata que nos mira pone en cuestión la autoconsciencia del hombre, en virtud de la cual él se mira siempre a través un punto de vista antropocéntrico, es decir, con la mirada de una gata antropomorfizada (espejo de lo humano y su mirada sobre sí como forma de auto-conciencia). Por contra, ver que la gata nos mira significa mirar a la gata con los ojos del cuerpo.

Tercera etapa: "quien habla es el 'yo"'.

Los padres del niño antes citado dicen "tú", dicen "yo", ubicados en el lenguaje para indicar sujetos diferentes, pero solo uno de esos sujetos es el "yo": quien habla. Entonces, el niño que no sabe quién es este "yo", comprende que solo quien habla es el "yo", y luego piensa que este "yo" es ajeno al niño mismo. Por esta razón el lenguaje habla solo. El niño es un "yo" solamente si dice "yo" y esto es angustioso porque no es el único "yo" que existe, existen tantos "yo" como hablantes hay. Y entonces, ¿quién es él? No solo el "yo" existe porque existe un "tú" que lo confirma, sino que esta nominación sirve también para impedirle al otro la posibilidad de ser un "yo" a su vez. Soy yo porque tú no lo eres. Se deviene humano solo condenando el otro a la inhumanidad. Devenir humano significa excluir alguien o algo de esta condición, a partir desde los animales y terminando con la propia animalidad. La «filosofía que vendrá», en palabras de Derrida, es el intento de pensar una salida del humanismo -que produce el sujeto metafísico que se basa en la exclusión.

\section{El lenguaje habla solo}

Hemos observado cómo la función del lenguaje es dominar la alteridad, que se puede entender como el cuerpo inmanente respecto a la trascendencia misma del lenguaje.

Siguiendo esta idea de un lenguaje autónomo e independiente del hablante (que lo controla), podemos decir que el hablante sufre los efectos y es impotente. Por lenguaje, Chomsky entiende un conjunto de frases construidas a partir de un alfabeto finito de fonemas. Estas frases pueden no tener significado (en cualquier sentido independiente de la expresión), 
y no deben ser necesariamente usadas por los hablantes ${ }^{37}$. No es el uso el que define el lenguaje, es decir, no son los hablantes, sus intenciones y sus fines comunicativos: el lenguaje es aquel particular "objeto" que existe también independientemente de nuestros cuerpos (de hecho, las frases de los idiomas "pueden no tener significado", y ¿qué hacemos, nosotros, con un lenguaje sin significado? El punto es este, el lenguaje no es hecho para nosotros) $)^{38}$.

¿Qué quiere decir Chomsky con esta impersonalidad del lenguaje? Lo que hace un lenguaje está contenido en el lenguaje mismo: un lenguaje es una cuestión de sintaxis (de forma), no de semántica ni de pragmática. El lenguaje tiene vida propia, y esta vida coincide con su gramática, que es un dispositivo que genera todas las frases gramaticales del lenguaje. Un lenguaje es un "dispositivo" que "genera" solo oraciones correctas, aunque ningún cuerpo humano utilizará estas oraciones ${ }^{39}$. Aquí vemos la paradoja del decir la no-verdad que al principio hemos utilizado como elemento del síntoma, de la forma latente de referirnos a los animales y sus simbologías.

Los seres humanos pueden hablar de lo que sus lenguajes les permiten formular, y esto implica también lo que no existe, a través del operador lógico de la negación. De este modo se convierten en accesibles para el pensamiento entidades que no existen realmente, simplemente porque podemos individuarlos como un "nuevo objeto" decible, cosa que nos aleja de los demás animales. Este pensamiento en constante avance se explica también en la cultura de los seres humanos: el pensamiento hipotético presupone la facultad biológica de la infinitud discreta. Es a través de esta capacitad específicamente humana que irrumpe lo posible en el mundo humano. Desde este momento, en que el animal humano es el animal de lo posible, todas las otras características sustanciales que son incluidas en su naturaleza devienen contingentes, es decir, no necesarias, porque en este punto se pueden cambiar ${ }^{40}$. El logos es la forma de la posibilidad de poder decir la no-verdad, de referirnos a algo que no existe y cambiar de

37 N. Chomsky, Saggi linguistici. Vol I, Turín, Boringhieri, 1969, 36.

38 F. Cimatti, Il taglio. Linguaggio e pulsione di morte, Macerata, Quodlibet, 2015, 66.

39 M. Hauser, N. Chomsky, T. Fitch, loc. cit.

40 F. Cimatti, Naturalmente comunista. Politica, linguaggio ed economia, Milán, Mondadori, 2011, p. 42. 
manera radical las formas de los entes que están implicados en el acto lingüístico. Fuera del logos, es decir, del lenguaje que domina las entidades, todo es accidental y azaroso, incognoscible e inalcanzable: "El sujeto no pertenece al mundo, sino que es más bien un límite del mundo" 41 .

\section{LA AUTORREFERENCIA}

[...] El hombre no tiene ninguna identidad específica, excepto la de poder reconocerse. Pero definir lo humano no a través de una nota characteristica, sino a través del conocimiento de sí, significa que es hombre el que se reconocerá como tal, que el hombre es el animal que tiene que reconocerse bumano para serlo ${ }^{42}$.

Ahora concentrémonos en la acción deconstructiva de Derrida, la cual sigue un preciso protocolo. La capacitad de autorreferencia remueve un hecho fundamental que surge a lo largo de los escritos del filósofo, es decir que: si concebimos aquel poder en un sentido amplio también el animal o algunos animales lo tienen, mientras, en un sentido estricto y riguroso también el hombre, al igual que los animales, está privado de él. La demostración deriva en una pregunta: ¿jpor qué hacer esto? Porque:

I) Porque esto debería permitir restituir a los animales, de forma diferenciada, el mismo poder que se reserva al hombre;

2) Evidenciar que el poder, considerado como prerrogativa del ser humano, por ejemplo, el poder de referirse a sí mismo de forma auto-deíctica, si es asumido y afirmado en una supuesta pureza, no puede ser atribuido ni siquiera al ser humano, porque de este poder o capacidad no poseemos un concepto puro y delimitable. No estamos en condiciones de identificarlo en su sentido propio.

La argumentación empieza poniendo en evidencia que:

a) En sentido amplio, no es cierto que esta autodeicticidad no esté funcionando en los animales.

41 L. Wittgenstein, Tractatus lógico-philosophicus, Madrid, Tecnos, 2013, p. 237.

42 G. Agamben, Lo abierto. El hombre y el animal, Buenos Aires, Adriana Hidalgo, 2002, p. 57. 
Ahora bien, por una parte, no es seguro que esa autodeicticidad no esté funcionando, de múltiples formas evidentemente, en cualquier sistema genético en general teniendo incluso cada elemento de la escritura genética, con el fin de significar dentro de la cadena genética, que identificarse, que marcarse de acuerdo cierta reflexividad. Tampoco es seguro que esa autodeicticidad no adopte unas formas muy desarrolladas, diferenciadas y complejas en un gran número de fenómenos sociales que podemos observar en el animote ${ }^{43}$.

Por ejemplo, ¿quién puede negar que la seducción como exhibición narcisista o la guerra sexual no pertenecen a una auto-mostración? En segundo lugar:

Ahora bien, por el contrario, y por otra parte, de acuerdo con lo que constituye aquí la matriz lógica de mi argumentación, no se trata únicamente de devolverle al animote lo que se le niega: por el axioma que permite conceder pura y simplemente al hombre o al animal razonable aquello de lo que se dice el animal sin más estaría privado ${ }^{44}$.

Esta consideración nos lleva a reflexionar sobre la forma rigurosa de pertenencia de este poder del logos al ser humano:

b) Si, como Derrida ya demostró en De la gramatología y La voz y el fenómeno, en la autoposición del "yo" se encuentra necesariamente implicado el paso a través el Otro, es decir, si la auto-afección pura, no mediada por ningún afuera, se revelase un mito y cada auto-afección fuera necesariamente hetero-afección, entonces esta autonomía del "yo" no sería ni pura ni rigurosa; no podría dar lugar a una delimitación simple y lineal entre el Hombre y el Animal. Si el "yo" se define, compone, construye a través del Otro, entonces no solo no es totalmente nuestro (de quien habla), sino que tampoco es puro. Entonces el hombre estaría desprovisto de aquella autodeicticidad "pura" por la cual se quiere identificar su ser específico, su superioridad.

Lo que deberíamos hacer, en conclusión, es devolver al animal este poder y también preguntarnos si el hombre tiene el derecho de atribuirse

43 J. Derrida, El animal que luego estoy si(gui)endo, Madrid, Trotta, 2008, 115.

44 Ibid., p. 116. 
184 Nicola Zengiaro

lo que rechaza al "animal"; si él mismo nunca ha tenido un concepto puro, riguroso e indivisible en cuanto tal. 